\title{
A family cluster of severe acute respiratory syndrome coronavirus 2 infections
}

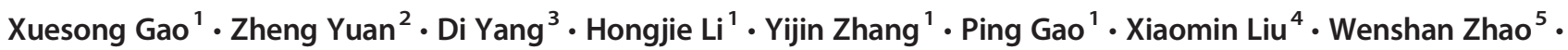 \\ $\mathrm{Te} \mathrm{Xiao}^{6} \cdot$ Xuefei Duan $^{1}$
}

Received: 27 February 2020 / Accepted: 24 March 2020 / Published online: 8 April 2020

(C) Springer-Verlag GmbH Germany, part of Springer Nature 2020

\begin{abstract}
Clinical and epidemiological knowledge of 2019 novel coronavirus disease (COVID-19) is limited. We reported a family cluster of severe acute respiratory syndrome coronavirus 2 (SARS-CoV-2) cases in Beijing, China. This family comprised three laboratory confirmed cases with clinical symptoms. All three patients had close contact with a relative from Wuhan, Hubei Province. Throat swab samples were all positive for SARS-CoV-2 using real-time reverse transcriptase-polymerase chain reaction assays. Chest computerized tomography revealed ground-glass opacities and consolidation. SARS-CoV-2 infections tend to clusters. Physicians should be aware of contact history so that infected patients can be identified promptly and further spreading prevented.
\end{abstract}

In December 19, a pneumonia called 2019 novel coronavirus disease (COVID-19) caused by severe acute respiratory syndrome coronavirus 2 (SARS-CoV-2) emerged in Wuhan, Hubei Province, China [1, 2]. As of February 20, 2020, there have been a total of 74,675 confirmed cases in China and 1073 confirmed cases outside of China [3]. Although SARS-CoV-2 was thought to have a zoonotic origin and early cases were reported to be associated with exposure to the seafood market in Wuhan, person-to-person transmission has been observed $[4,5]$. At present, the emergence, development, and underlying mechanism of immunity and clinical outcomes of patients with COVID-19 outside Wuhan are limited. Here, we report

Xuefei Duan

duanxuefei@vip.sina.com

1 Department of General Medicine, Beijing Ditan Hospital, Capital Medical University, Beijing, China

2 Department of Orthopedics, Beijing Ditan Hospital, Capital Medical University, Beijing, China

3 Center of Infectious Disease, Beijing Ditan Hospital, Capital Medical University, Beijing, China

4 Department of Oncology, Beijing Ditan Hospital, Capital Medical University, Beijing, China

5 Center of Liver Diseases, Beijing Ditan Hospital, Capital Medical University, Beijing, China

6 Department of Neurosurgery, Beijing Ditan Hospital, Capital Medical University, Beijing, China the epidemiologic and clinical features of a family cluster of SARS-CoV-2 infections that occurred in Beijing who did not have a history of travel to Wuhan.

Patient 1 was a 72-year-old female with hypertension. She presented to the emergency department with $10 \mathrm{~h}$ of fever (maximum temperature of $38.1{ }^{\circ} \mathrm{C}$ ) and muscle soreness in the late evening of February 2, 2020. The patient's oxygen saturation was $98 \%$ while she was breathing ambient air. A chest $\mathrm{CT}$ scan showed ground-glass opacities in the upper lobe of the right lung (Fig. 1). After admission, she initially received antiviral therapy with lopinavir/ritonavir and aerosol inhalation of interferon-alpha in addition to supplemental oxygen delivered by nasal cannula at $2 \mathrm{~L}$ per min. She was diagnosed with COVID-19 because her throat swab sample was nucleic acid-positive for SARS-CoV-2 [6]. Laboratory results are summarized in Table 1. On the second hospital day, she developed intermittent atrial fibrillation. She was treated with low dose of betaloc. The patient was still feverish with the maximum temperature of $39^{\circ} \mathrm{C}$, and she received antipyretic therapy. A second chest CT revealed bilateral lung disease with an increasing number of ground-glass opacities and a crazy-paving pattern in February 7. In February 10, she complained of worsening dyspnea. Oxygen saturation decreased to $90-92 \%$ while the patient was breathing $10 \mathrm{~L}$ of oxygen with the use of an oxygen mask. Blood-gas evaluations showed type I respiratory failure. She was transferred to the intensive care unit (ICU) immediately, where she received high-flow nasal oxygen therapy. She was finally intubated and 


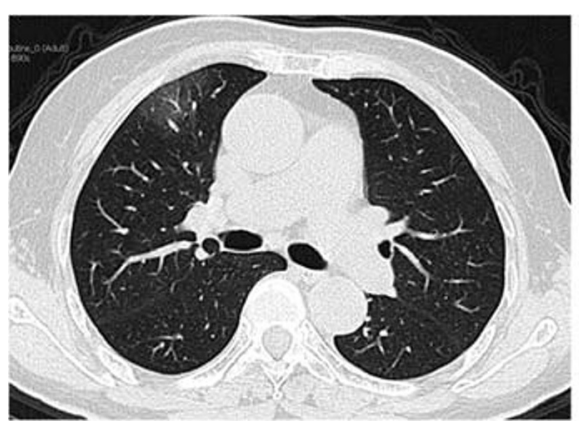

February 2

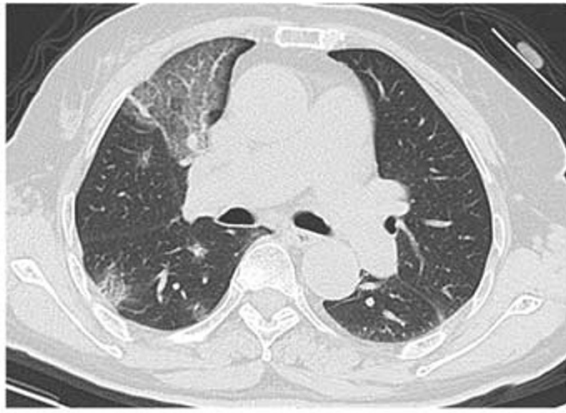

February 7

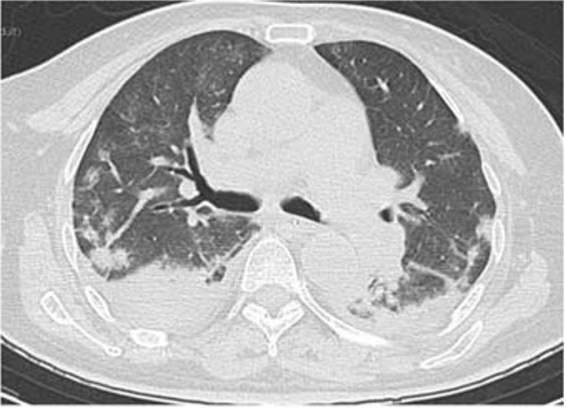

February 19

Fig. 1 Chest CT of patient 1

given mechanical ventilation for severe acute respiratory distress syndrome (ARDS) in February 14. A third chest CT showed decreased ground-glass opacities, and her fever finally resolved in February 19. However, her throat swab sample was still nucleic acid-positive in February 19.

Patient 2 was a 47-year-old male and the son of patient 1. They presented to the emergency department on February 2,
2020. He complained of a 5-day history of high fever (maximum temperature of $39.2{ }^{\circ} \mathrm{C}$ ), and cough. A chest CT scan showed bilateral ground-glass opacities with consolidation (Fig. 2). A throat swab nucleic acid test was positive for SARS-CoV-2. After admission, he was also treated with lopinavir/ritonavir and aerosol inhalation of interferon-alpha. However, his condition deteriorated with high fever $\left(40.0^{\circ} \mathrm{C}\right)$
Table 1 Clinical laboratory results of patients with COVID19 on admission to hospital

\begin{tabular}{|c|c|c|c|c|}
\hline Variables & Case 1 & Case 2 & Case 3 & Reference range \\
\hline Age & 72 & 47 & 45 & \\
\hline Gender & Female & Male & Female & \\
\hline White blood cell count $\left(\times 10^{9} / \mathrm{L}\right)$ & 2.99 & 2.96 & 4.9 & $4-10$ \\
\hline Neutrophil count $\left(\times 10^{9} / \mathrm{L}\right)$ & 1.98 & 1.63 & 2.94 & $2-8$ \\
\hline Lymphocyte count $\left(\times 10^{9} / \mathrm{L}\right)$ & 0.76 & 1.07 & 1.63 & $1-5$ \\
\hline Eosinophil count $\left(\times 10^{9} / \mathrm{L}\right)$ & 0.01 & 0.00 & 0.01 & $0.02-0.5$ \\
\hline Hemoglobin $(\mathrm{g} / \mathrm{L})$ & 131 & 157 & 109 & $110-150$ \\
\hline Platelet count $\left(\times 10^{9} / \mathrm{L}\right)$ & 156 & 133 & 263.4 & $100-300$ \\
\hline Alanine aminotransferase (U/L) & 18.9 & 83.7 & 25.1 & $7-40$ \\
\hline Alanine aminotransferase (U/L) & 19.5 & 46.3 & 28.1 & $13-35$ \\
\hline Total bilirubin $(\mu \mathrm{mol} / \mathrm{L})$ & 9.7 & 8.3 & 5.5 & $0-18.8$ \\
\hline Creatine $(\mu \mathrm{mol} / \mathrm{L})$ & 61.1 & 88.1 & 51.9 & $\begin{array}{l}\text { Male, 57-97 } \\
\text { female, 41-73 }\end{array}$ \\
\hline C-Reactive protein $(\mathrm{mg} / \mathrm{L})$ & 2.7 & 7.4 & 1.4 & $0-5$ \\
\hline Lactate dehydrogenase (U/L) & 161.4 & 200.9 & 366.9 & $120-250$ \\
\hline Creatine kinase $(\mathrm{U} / \mathrm{L})$ & 38.1 & 72.2 & 111.1 & $40-200$ \\
\hline Creatine kinase-MB (U/L) & 16.3 & 14.2 & 50.1 & $<25$ \\
\hline$\alpha$-Hydroxybutyric dehydrogenase (U/L) & 130 & 155 & 324 & $74-182$ \\
\hline Troponin I ( $\mu \mathrm{g} / \mathrm{L})$ & $<0.01$ & $<0.01$ & $<0.01$ & $<0.01$ \\
\hline Procalcitonin $(\mathrm{ng} / \mathrm{mL})$ & $<0.05$ & $<0.05$ & $<0.05$ & $<0.05$ \\
\hline Serum amyloid $\mathrm{A}(\mathrm{mg} / \mathrm{L})$ & 6.3 & 106.4 & 6.5 & $0-10$ \\
\hline Prothrombin time (s) & 12.4 & 13.3 & 12 & $9.4-12.5$ \\
\hline International normalized ratio & 1.15 & 1.23 & 1.11 & $0.8-1.2$ \\
\hline D-Dimer (mg/L) & 0.76 & 0.31 & 0.50 & \\
\hline CD4 $(\operatorname{cell} / \mu \mathrm{L})$ & 180 & 285 & 511 & $706-1125$ \\
\hline CD8 $($ cell $/ \mu \mathrm{L})$ & 253 & 126 & 729 & $320-1250$ \\
\hline $\mathrm{NK}($ cell $/ \mu \mathrm{L})$ & 37 & 51 & 444 & $90-590$ \\
\hline B $($ cell $/ \mu \mathrm{L})$ & 147 & 104 & 189 & $90-660$ \\
\hline Lactate $(\mathrm{mmol} / \mathrm{L})$ & 2.05 & 2.05 & 1.48 & $1.33-1.78$ \\
\hline
\end{tabular}


Fig. 2 Chest CT of patient 2

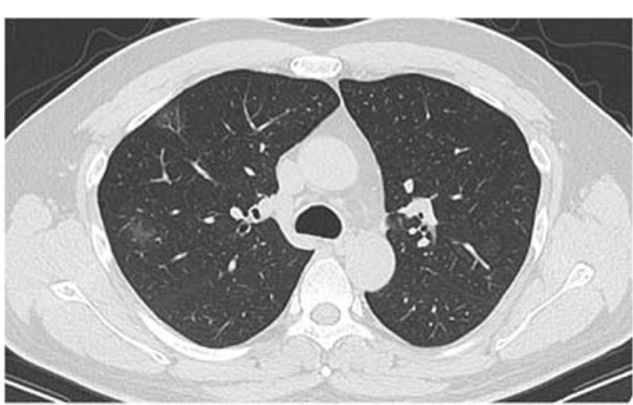

February 2

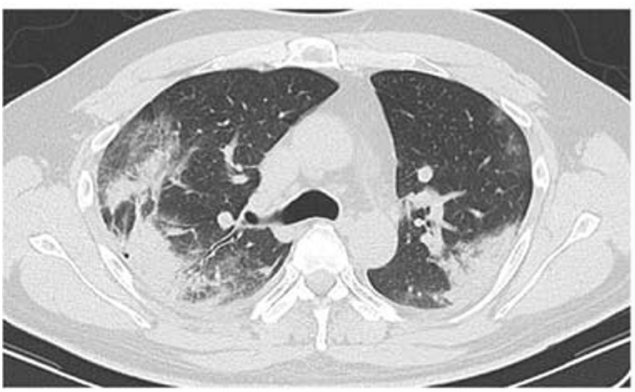

February 13

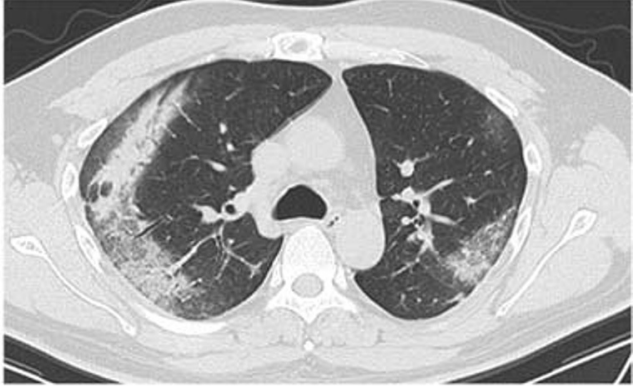

February 8

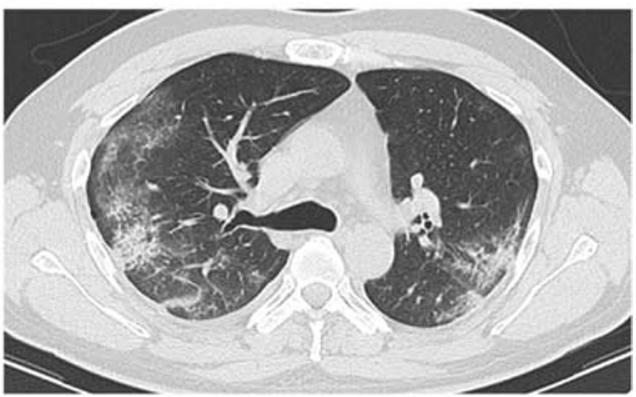

February 18 and shortness of breath. A second chest CT showed extensive bilateral ground-glass opacities and consolidation in February 8. Blood-gas evaluations showed type I respiratory failure. Then, he was transferred to the ICU with ARDS. The patient's oxygenation improved with high-flow nasal oxygen. His fever resolved in February 9. His nucleic acid test became negative after February 15. His clinical conditions improved, and he was transferred back to the general ward in February 18. He continued to receive supplemental oxygen delivered by nasal cannula at $2 \mathrm{~L}$ per min. His oxygen saturation remained at $98 \%$.

Patient 3 was a 45-year-old female and the wife of patient 2 . They presented to the emergency department on February 2,2020 . She complained of having fever (maximum temperature of $37.7^{\circ} \mathrm{C}$ ) and cough for 5 days. A chest CT scan showed bilateral ground-glass opacities and consolidation in the lower right lobe (Fig. 3). A throat swab sample was positive for SARS-CoV-2. She received lopinavir/ritonavir and aerosol inhalation of interferon-alpha. Her fever resolved from the second hospital day. Results of routine blood counts and blood-gas evaluations were normal. A chest CT scan revealed partial absorption of the lesion in February 14. However, she was still hospitalized due to the persistent positive nucleic acid tests.

Here we report a familial cluster of pneumonia due to SARS-CoV-2 infection. The family cluster of 3 patients (patients 1-3) drove from Beijing to Xinyang, Henan Province, on January 24, 2020. The family stayed in their own house throughout their trip. They shared meals with a relative from Wuhan on January 27, 2020. They had no history of contact with other people with fever or respiratory tract symptoms, contact with wild animals, visits to the Huanan seafood market in Wuhan, or consumption of game meat in restaurants. After they drove back to Beijing on January 27, 2020, the 3 patients lived in one apartment. Patient 1 stayed in one room while patients 2 and 3 stayed in another. Patients 2-3

Fig. 3 Chest CT of patient 3

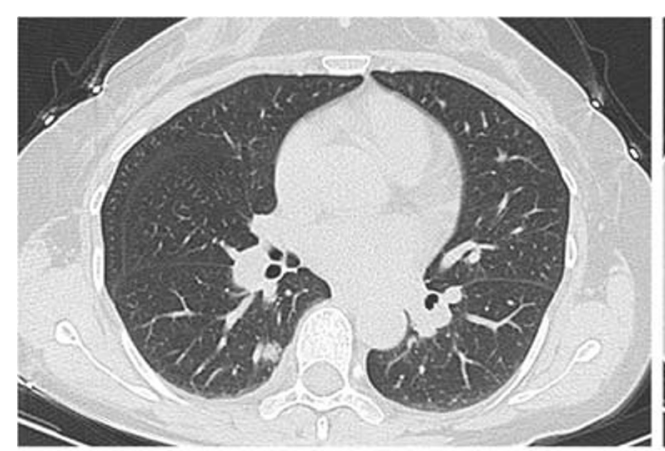

February 2

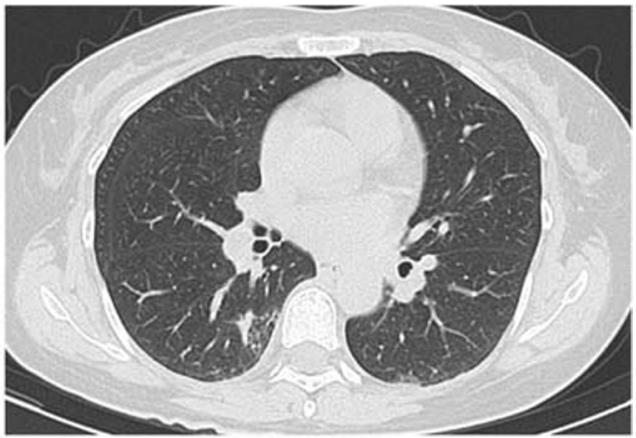

February 15 
presented with fever and cough on January 29, 2020. Patient 1 presented with fever on February 2, 2020. The incubation period was estimated to be between 2 and 6 days. The most likely course of transmission was that patients $1-3$ acquired the infection from their relative from Wuhan, while sharing meals. Their relative might has acquired the infection from the community, as he had no clear exposure history. According to what they had been told, the relative from Wuhan was isolated. However, he did not receive a nucleic acid test because he has no symptoms.

All three patients successively presented with fever. The symptoms of this COVID-19 are also nonspecific, and fever is the most common symptom [7, 8]. Although patients 1-2 had mild symptoms at the time of admission, their dyspnea worsened in 7-10 days from the time of onset. The dynamic changes in chest CT scans were also consistent with clinical course. Therefore, radiological assessment of patients' progress plays an important role in the management of COVID-19. Currently, no specific antiviral treatment exists. Clinical management focuses on symptomatic treatment, with organ support for critically ill patients. Lopinavir/ritonavir and aerosol inhalation of interferon-alpha were used as soon as they were admitted. However, their clinical courses diverged. The conditions of patient 1 became aggravated with positive nucleic acid tests; however, patient 3 resolved with a positive nucleic acid test. Further randomized controlled trials are needed to evaluate efficacy of these antiviral medications, including remdesivir [9]. The pathophysiology mechanism of severity levels caused by SARS-CoV-2 is not well understood. It has been found to be associated with a cytokine storm, which is characterized by increased plasma concentrations of IL-2, IL7, IL-10, MCP-1, MIP-1 $\alpha$, and TNF- $\alpha$ in critical patients according to previous studies [10-12]. Xu et al. postulated overactivation of $\mathrm{T}$ cells may partly account for the severe immune injury [13]. These excessive immune responses lead to further lung injury. Corticosteroids were used frequently to treat severe patients. Huang et al. treated few severely ill patients with ARDS with low-to-moderate doses of corticosteroids [11]. Systemic corticosteroid was given to $44.5 \%$ of severe cases and $13.7 \%$ of non-severe cases [7]. However, none of these treatments were found to be effective $[8,14]$. In this setting, administration of corticosteroids has been conditionally recommended in our guidance [6], but it has not been recommended by the WHO [15]. Intravenous injection with $\gamma$-immunoglobulin may be an alternative [14]. However, more clinical data are required to evaluate it.

In conclusion, cases of COVID-19 tend to emerge in clusters. No specific therapeutics are available for treatment of COVID-19. Physicians should be aware of contact history for patients to promptly identify patients and prevent further spreading. Early diagnosis, early isolation, and early management are crucial to curbing transmission and reducing mortality.
Acknowledgments We thank LetPub (www.letpub.com) for its linguistic assistance during the preparation of this manuscript.

Author contributions This study was designed by Xuefei Duan, Xuesong Gao, and Di Yang. The data were collected by Zheng Yuan, Hongjie Li, Yijin Zhang, Ping Gao, and Te Xiao. The manuscript was drafted and written by Xiaomin Liu and Wenshan Zhao; revised by Xuefei Duan and Xuesong Gao; and finally reviewed by all the authors. All authors approved the final version for submission and are able to account for its content.

Funding information This study received funding from construction of high-level health technical personnel in the Beijing health system (20143-093) and China's National Science and Technology Major Project (2018ZX10715-005-003-002).

\section{Compliance with ethical standards}

Conflict of interest The authors declared that they have no competing interests.

Ethical approval This study was approved by the Ethics Committee of Beijing Ditan Hospital.

\section{References}

1. Zhu N, Zhang D, Wang W et al (2020) A novel coronavirus from patients with pneumonia in China, 2019. N Engl J Med 382:727733

2. World Health Organization (2019) https://www.who.int/ emergencies/diseases/ novel-coronavirus-2019. Accessed Feb 20, 2020

3. World Health Organization (2019). https://www.who.int/docs/ default-source/ coronaviruse/situation-reports/20200220-sitrep-31covid-19.pdf?sfvrsn= dfd11d24_2. Accessed Feb 20, 2020

4. Chan JF-W, Yuan S, Kok K-H et al (2020) A familial cluster of pneumonia associated with the 2019 novel coronavirus indicating person-to-person transmission: a study of a family cluster. Lancet 395:514-523

5. Li Q, Guan X, Wu P et al (2020) Early transmission dynamics in Wuhan, China, of novel coronavirus-infected pneumonia. N Engl J Med. https://doi.org/10.1056/NEJMoa2001316

6. Diagnosis and Treatment protocol for COVID-19 pneumonia (the sixth edition) (2020).http://www.nhc.gov.cn/xcs/zhengcwj/202002/ 8334a8326dd94d 329df351d7da8aefc2.shtml (in Chinese). Accessed Feb 20, 2020

7. Guan W-j, Ni Z-y, Hu Y et al (2020) Clinical characteristics of 2019 novel coronavirus infection in China. N Engl J Med. https://doi.org/ 10.1056/NEJMoa2002032

8. Wang D, Hu B, Hu C et al (2020) Clinical characteristics of 138 hospitalized patients with 2019 novel coronavirus-infected pneumonia in Wuhan, China. JAMA. https://doi.org/10.1001/jama. 2020.1585

9. Holshue ML, DeBolt C, Lindquist S et al (2020) First case of 2019 novel coronavirus in the United States. N Engl J Med. https://doi. org/10.1056/NEJMoa2001191

10. Li G, Fan Y, Lai Y et al (2020) Coronavirus infections and immune responses. J Med Virol. https://doi.org/10.1002/jmv.25685

11. Huang C, Wang Y, Li X et al (2020) Clinical features of patients infected with 2019 novel coronavirus in Wuhan, China. Lancet 395: 497-506 
12. Zumla A, Hui DS, Azhar EI et al (2020) Reducing mortality from 2019-nCoV: host-directed therapies should be an option. Lancet 395:e35-e36

13. Xu Z, Shi L, Wang Y et al (2020) Pathological findings of COVID19 associated with acute respiratory distress syndrome. Lancet Respir Med. https://doi.org/10.1016/s2213-2600(20)30076-x

14. Kui L, Fang YY, Deng Y et al (2020) Clinical characteristics of novel coronavirus cases in tertiary hospitals in Hubei Province. Chin Med J. https://doi.org/10.1097/CM9.0000000000000744
15. World Health Organization (2019) https://www.who.int/ publications-detail/ clinical-management-of-severe-acuterespAiratory-infection-when-novel-coronavirus-(ncov)-infectionis-suspected. Accessed Feb 20, 2020

Publisher's note Springer Nature remains neutral with regard to jurisdictional claims in published maps and institutional affiliations. 